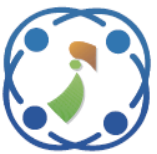

\title{
Fuzzy Logic-Integral Backstepping Control for PV Grid-Connected System with Energy Storage Management
}

\author{
Saloua Marhraoui $^{1 *} \quad$ Ahmed Abbou $^{1} \quad$ Zineb Cabrane $^{1} \quad$ Salah Eddine Rhaili $^{1} \quad$ Nezha El Hichami $^{1}$ \\ ${ }^{I}$ Department of Electrical Engineering, Mohammadia School of Engineers (EMI), \\ Mohammed V University in Rabat, Morocco \\ *Corresponding author's Email: saloua.marhraoui@gmail.com
}

\begin{abstract}
To solve the problems of nonlinearity and power fluctuation linked on the Photovoltaic panel (PV) connected storage system and grid, because of the temperature and irradiation variation. We integrated three parts of the control. The first part, dedicated to developing an algorithm to eliminate the nonlinearity; therefore, we have obtained the Maximum Power Point Tracking (MPPT) via the control of the duty cycle of DC/DC boost converter. Consequently, to achieve the MPPT, we combined between tow algorithms Fuzzy Logic and Integral Backstepping (Fuzzy Logic-Integral Backstepping Controller) as a new strategy of MPPT. This MPPT based on the performances of the Fuzzy Logic Controller (FLC) as an estimator of the reference voltage, next, we apply the Integral Backstepping approach to generate the law control founded on the Lyapunov theory to augment the robustness and stability of the PV connected storage system and grid. Then, in the second part of the control, we add a Batteries Energy Storage System with a control management algorithm in the DC/DC side to eliminate any fluctuation of the output power of the PV system. In the third part of the control linked to the grid side, we use the three-phase Voltage Source Inverter Control (VSIC) as a charge controller for the stability of the grid parameters.
\end{abstract}

Keywords: PV, DC/DC boost, Fuzzy logic-integral backstepping, Batteries energy storage system, DC/AC inverter.

\section{Nomenclature}

$\boldsymbol{I}_{\boldsymbol{p h}}:$ Insolation current

$I_{s}:$ Reverse saturation current

$\boldsymbol{R}_{\boldsymbol{s}}$ : Series resistance

$\boldsymbol{R}_{\boldsymbol{s} \boldsymbol{h}}$ : Parallel resistance

$V_{T}$ : Thermal voltage

$K$ : Boltzman constat

T: Cell Temperature in Kelvin

$q$ : Charge of an electron

$\gamma$ : Factor of ideality

$\boldsymbol{G}$ : Solar irradition

$\boldsymbol{T}_{r}$ : The cell reference temperature

$\boldsymbol{I}_{\boldsymbol{r} r}$ : The cell reverse saturation at temperature $T_{r}$

$\boldsymbol{E}_{\boldsymbol{G}_{0}}$ : Band gap of the semiconductor used in the cell

$I_{s c r}$ : The cell short-circuit current at reference temperature and irradiation

$\boldsymbol{K}_{\boldsymbol{i}}$ : Short circuit current temperature coefficient $\boldsymbol{N}_{\boldsymbol{s}}$ : Number series PV $v_{p}$ : Average state of the PV output voltage

$\boldsymbol{i}$ : Average state of the PV output current

$\boldsymbol{P}_{\boldsymbol{p}}$ : PV panel output power

$\boldsymbol{i}_{\boldsymbol{L}}:$ DC/DC Boost inductor output current

$\boldsymbol{u}=\boldsymbol{\alpha}$ : Boost converter duty cycle

$\boldsymbol{L}$ : The DC/DC boost inductor

$\boldsymbol{C}_{\boldsymbol{P}}$ : The Boost converter input capacitor

$\boldsymbol{C}_{\boldsymbol{m}}$ : The Boost converter output capacitor

$V_{P V-r e f}$ : PV Reference voltage

$V_{\boldsymbol{d} c}$ : DC/DC Boost output voltage

$\boldsymbol{i}_{C}$ : VSIC input current

$\boldsymbol{d}_{1 \boldsymbol{a b c}}, \boldsymbol{d}_{2 \boldsymbol{a b} c}$ : VSIC Duty cycles

$V_{P 1}$ : Phase denotes peak voltage

$\boldsymbol{\omega}_{\boldsymbol{s}}$ : Angular frequency

$\boldsymbol{f}_{\boldsymbol{s}}:$ Frequency system

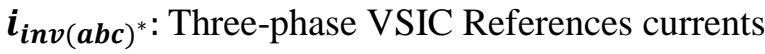

$\boldsymbol{i}_{L(\boldsymbol{a} \boldsymbol{a} c)}:$ Load currents

$\boldsymbol{d}_{1 a}, \boldsymbol{d}_{1 b}$ and $\boldsymbol{d}_{1 c}$ : VSIC Control signals

$\boldsymbol{d}_{\boldsymbol{d q}}$ : Signal of phased locked loop (PLL) 
$\boldsymbol{d}_{\boldsymbol{d q}}, \boldsymbol{d}_{\boldsymbol{d i n v}}$ : VSI currents

$\boldsymbol{d}_{\boldsymbol{d}}, \boldsymbol{d}_{\boldsymbol{q}}$ : Load to AWPI current controllers

$\boldsymbol{u}_{\boldsymbol{d q}}$ : AWPI output current controllers in d-q axis

$v_{\boldsymbol{d q}}$ : PCC voltages

$\boldsymbol{i}_{\text {invdq }}$ : AWPI output current controllers in d-q axis

$\boldsymbol{L}_{\boldsymbol{f}}$ : Output VSI inductor

$\boldsymbol{V}_{\text {ref }}$ : Reference voltage

$\boldsymbol{I}_{\boldsymbol{d} c_{r e f}}:$ Reference current of DC bus

$I_{\text {bat }_{\text {ref }}}$ : Reference current of batteries

$S_{\text {So }} C_{\text {bat }}$ : State of charge of batteries

$\boldsymbol{L}_{\boldsymbol{b}}$ : Batteries inductor

$\boldsymbol{R}_{\boldsymbol{b}}$ : Batteries resistance

$\boldsymbol{E}_{\boldsymbol{b}}$ : Batteries electromotive force

$\boldsymbol{C}_{\boldsymbol{b a t}}:$ Batteries capacitor

$\boldsymbol{V}_{\boldsymbol{c b a t}}$ : Batteries capacitor voltage

$\boldsymbol{V}_{\boldsymbol{b}}$ : Batteries voltage

$D_{\text {bat }}:$ Batteries duty cycle

$\boldsymbol{k}_{\boldsymbol{i}_{\boldsymbol{d c}}}, \boldsymbol{k}_{\boldsymbol{P}_{\boldsymbol{d c}}}$ : PI bus voltage

$\boldsymbol{C}_{\text {buck_boost_out }}$ : Buck-Boost output capacitor

$\boldsymbol{L}_{\text {buck_boost }}$ : Buck-Boost inductor

$\boldsymbol{K}_{\boldsymbol{i}_{\text {bat }}}, \boldsymbol{K}_{\boldsymbol{P}_{\text {bat }}}$ : PI batteries, Buck-Boost controller

$\mathbf{k 1}, \mathbf{k 2}$ and k3: Fuzzy logic adaptive gains

$\boldsymbol{K}_{\mathbf{1}}, \boldsymbol{K}_{\mathbf{2}}$ : Backstepping adaptive gains

$\boldsymbol{y}_{\boldsymbol{d}}$ : Controlled output of PV system

\section{Introduction}

Nowadays, we notice the rapid development of the PV connected energy storage system and the grid [1]. In our work we chose the last system with a new design of control to obtain a good profitability. The controllers confronted with many challenges to maintain the stability and viability of the grid. In this work, we targeted realize three controllers to regulate three problems in the PV connected storage system and the grid [2], the first is the design of a good MPPT algorithm to achieve a maximum power of the PV that feeds the system, the second is the management of power storage system, and, the triad is controlled the three-phase voltage source inverter to maintaining the grid parameters at desired values. These all last controllers are designed to solve the problems caused by the influence of climatic conditions, which include irradiation, temperature as major conditions, and the impact of the load in the system [3,4]. Absolutely, the climatic conditions are uncontrollable, it is obligatory to elaborate an MPPT technique to control the DC/DC boost converter, to obtain the optimum power from the PV also, the stabilty of PV voltage. Therefore, a batteries energy storage system with management considered the DC/DC side of the PV system to recompense the inconsistency of the PV output power during the change of irradiation and temperature [5, 6].

In our PV system, we have tow conduction sides: The DC side that has the MPPT control the DC/DC boost and the energy storage management control. The AC side: When we have the DC/AC inverter needs to control because it connects between the DC side and the grid-load side. This controller is based on a voltage-by-voltage source inverter controller and injects no harmonic current into the grid via using the filters $[7,8]$.

All studies have been oriented towards the PV connected storage system and the grid based on robust and intelligent controllers. However, these controllers some limitation in the design of the PV system and control. The study [9] gives a satisfying result but the results have some disturbance and lack of stability in the power and current. In [10] authors proposed different loads used in the simulation control effect, in the parallel operation of many distributor-resource units for a voltage and frequency control strategy for the distributor energy resource system. However, the authors did not use the energy storage unit and the system in the simulation. Also in [11], the study based on sliding mode control as an MPPT. Then the Lyapunov function-analyzed control method implemented in VSCI, the simulation give that the controller had good control results. However, the control strategy presented in this work has some limitations; in addition, the energy storage system not considered. In work [12], the authors compare a Backstepping in three methods to control the DC/DC Buck-Boost with simple load and the system design still poor compared to the our proposed PV system.

In this work we implement the Fuzzy LogicIntegral Backstepping controller in the PV connected energy storage system and the grid, to achieve the PV maximum power and to stable the output boost voltage. The Fuzzy Logic-Integral Backstepping controller had a better effect on the level of stability of the PV system. The linear control approaches have been widely used to power converters $[13,15,16]$. Because wide nonlinear control techniques developed to find a good solution for the problems of the nonlinearity linked to the solar system and power converters $[17,19,20]$. As a natural approach of nonlinear control, The Fuzzy Logic-Integral Backstepping used in the PV system deals with the nonlinearity and doubt [21-23]. We designed the Fuzzy Logic-Integral Backstepping controller in the PV power supply system, by controlling the duty cycle of the DC-DC boost circuit; also, make the DC side voltage stable. However, the energy storage unit 


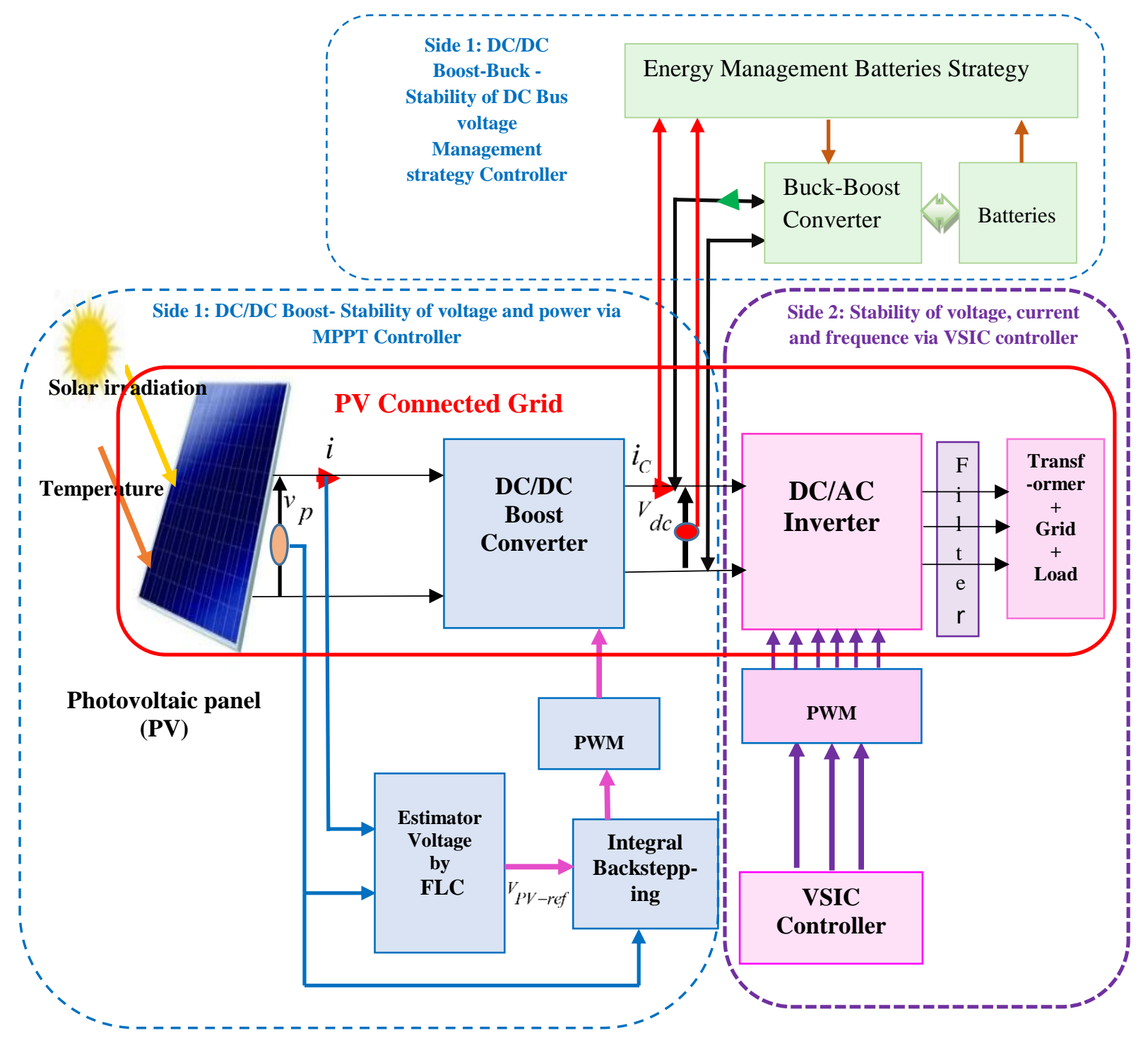

Figure. 1 Diagram block of PV connected storage system and grid

considered in the system has a positive influence on the system thanks to the management strategy. It is the best solution to use photovoltaic energy because of the variation of load demand that requires energy storage with high power density and ability. Batteries are relatively mature technology; they characterized high energy density. In addition, a good technique added to MPPT and compensate power when low, and stores energy when there is excess in order to make a system work at the best performances $[24,25]$. we proposed in the DC/AC inverter side [26, 27] a VSIC strategy to control the voltage and frequency for the distributed energy in different types of loads of grid. In the DC/AC inverter side, it ensures that the harmony is within the scope. Consequently, we verify the effectiveness of the VSIC by simulation. We prove the effective grid strategy via estimating the unknown parameters in the system and achieve satisfactory control performance in the grid [28].
Finally, the controllers stabilize the DC bus voltage and makes the power injected in the grid at a stable value. Because of the Fuzzy Logic is a robust estimator of reference voltage and the Integral Backstepping law based on the Lyapunov stability theory to augment the performances of the PV system. Additionally, the management of the storage system adds to the control system improvement and robustness of the controller design secures energy storage. The VSIC and the filters solves the problems of the differential expansion of the virtual control signal, and the control input saturation. We organize our work as in section 2: The model of the PV system established with VISC. Section 3: Focused on batteries energy storage system with a management strategy. Section 4: Reserved for The Fuzzy LogicIntegral Backstepping controller for DC/DC converter. In section 5: We demonstrated the advance of the designed controller proposed in 
MATLAB/Simulink. Finally, we give perspectives and conclusions in section 6 .

\section{PV connected grid system - Description and modelling design}

The system chose to study in our work show in Fig.1. The PV system composed of a PV generator connected to the boost converter to elevating the PV voltage with an MPPT algorithm. We add the Batteries Energy Storage System with management in the DC/DC side. We link the DC side to DC/AC side via the DC/AC inverter to supply a load and grid we use VSIC to keep the frequency, current and voltage at stable values in the grid and load.

\subsection{PV panel mathematical model}

The electrical circuit of a PV generator (PVG) designed as shown in Fig.2, the array panel formed by different photovoltaic cell series to give electricity under climatic conditions: Solar irradiation and temperature. The mathematical model of the electrical model of PVG presented in the equation linking current and voltage $[29,30]$ :

$$
I=I_{p h}-I_{S}\left[\exp \left(\frac{v_{p}+I R_{s}}{N_{\gamma} V_{T}}\right)\right]-\frac{v_{p}+R_{s} i}{R_{s h}}
$$

The photocurrent depends on the temperature and irradiation:

$$
\begin{gathered}
I_{s}=I_{r r}\left[\frac{T}{T_{r}}\right]^{3}\left[\exp \left(\frac{E_{G 0}}{\gamma K}\left(\frac{1}{T_{r}}-\frac{1}{T}\right)\right)\right] \\
I_{p h}=\left[I_{s c r}+K_{i}\left(T-T_{r}\right)\right] \frac{G}{1000}
\end{gathered}
$$

We use the curves Fig. 1 (a) gives characteristic current-voltage and Fig. 1 (b) present power-voltage characteristic to analyze the performance of a PVG with conditions:

Solar irradiation : $\mathrm{G}=1000 \mathrm{w} / \mathrm{m}^{2}$.

Temperature values : $\mathrm{T}=0^{\circ} \mathrm{C}, \mathrm{T}=25^{\circ} \mathrm{C}$ and $\mathrm{T}=50^{\circ} \mathrm{C}$

The condition of maximum power point following by the Eq. (4):

$$
\frac{\partial P_{p}}{\partial v_{p}}=\frac{\partial v_{p} i}{\partial v_{p}}=i+v_{p} \frac{\partial v_{p}}{\partial v_{p}}=0
$$

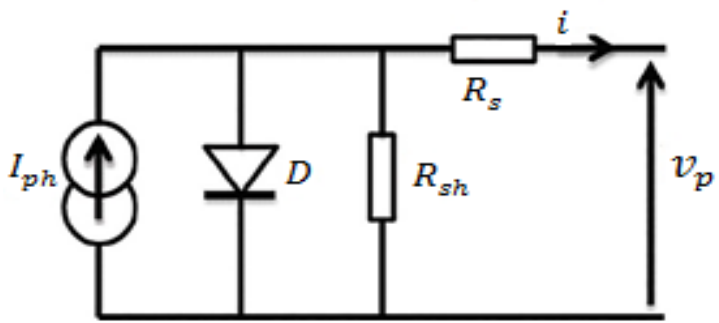

Figure. 2 Model of the generator photovoltaic
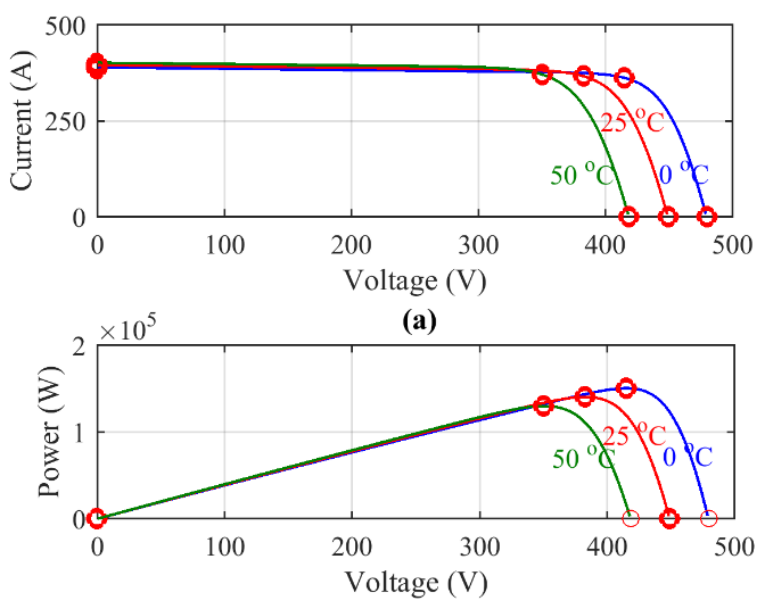

(b)

Figure. 3 PV Curves with G constant and T variable:

(a) current-Voltage and (b) power-voltage

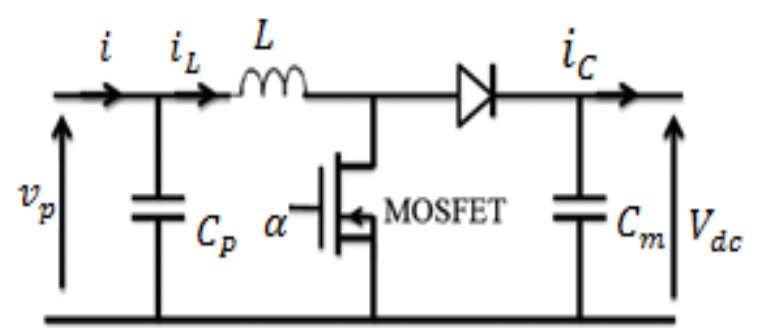

Figure. 4 Circuit of boost power converter

\subsection{DC/DC boost mathematical model}

We used a boost converter present in Fig. 4 in the PV connected grid system for converting the low voltage to the higher voltage obtained from the PV panel. Usually, the basic electrical circuit of boost is constructed: One switch (typically MOSFET, IGBT or BJT), inductor and, capacitor. The boost shown in Fig. 3 designed such as an input filter $\left(C_{p}, L\right)$ and an output filter $\left(C_{m}\right)$ where, $\alpha$ is the control signal that can take two discrete values 0 and 1 (Switch Open/Switch Closed). Therefore, we change the duty cycle to get the maximum power point of the photovoltaic generator, via the principal method based on calculating the average state $[31,32]$, the dynamics of the DC/DC boost conduction mode in our system: 


$$
\left\{\begin{array}{c}
C_{p} \frac{d v_{p}}{d t}=i-i_{L} \\
L \frac{d i_{L}}{d t}=v_{p}-(\& 1-\alpha) V_{d c} \\
c_{m} \frac{d v_{d c}}{d t}=-i_{C}+(1-\alpha) i_{L}
\end{array}\right.
$$

\subsection{Model of control the three-phase DC/AC voltage source inverter (VSI) and grid}

The electrical model of the three-phase DC/AC Voltage source inverter (VSIC) and the grid shown in Fig. 5.

To control the frequency, the current, voltage and power of a three-phase inverter, balancing of loads, and harmonics. To maintain a constant frequency, we used the voltage source inverter control VSIC controller.
To maintain the frequency and voltage at a constant value, the VSIC forced the system to work at the desired frequency and voltage via strategy control, even if of perturbations in the grid, we are proposed Anti-Windup proportional-integral (AWPI) and Anti-Windup proportional-resonant (AWPRC) controllers to avoid the saturation. As present in Fig.6, we are combined two types of control techniques to realize the tasks simultaneously when the PV system connected grid is operating. Select the right control based on the output received from the data from the grid. The study, one supposes that the condition to choose the perfect control from the source current. Therefore, if the current value is equal to zero, the selector chooses $d_{1 a b c}$, alternatively, $d_{2 a b c}$ still selected.

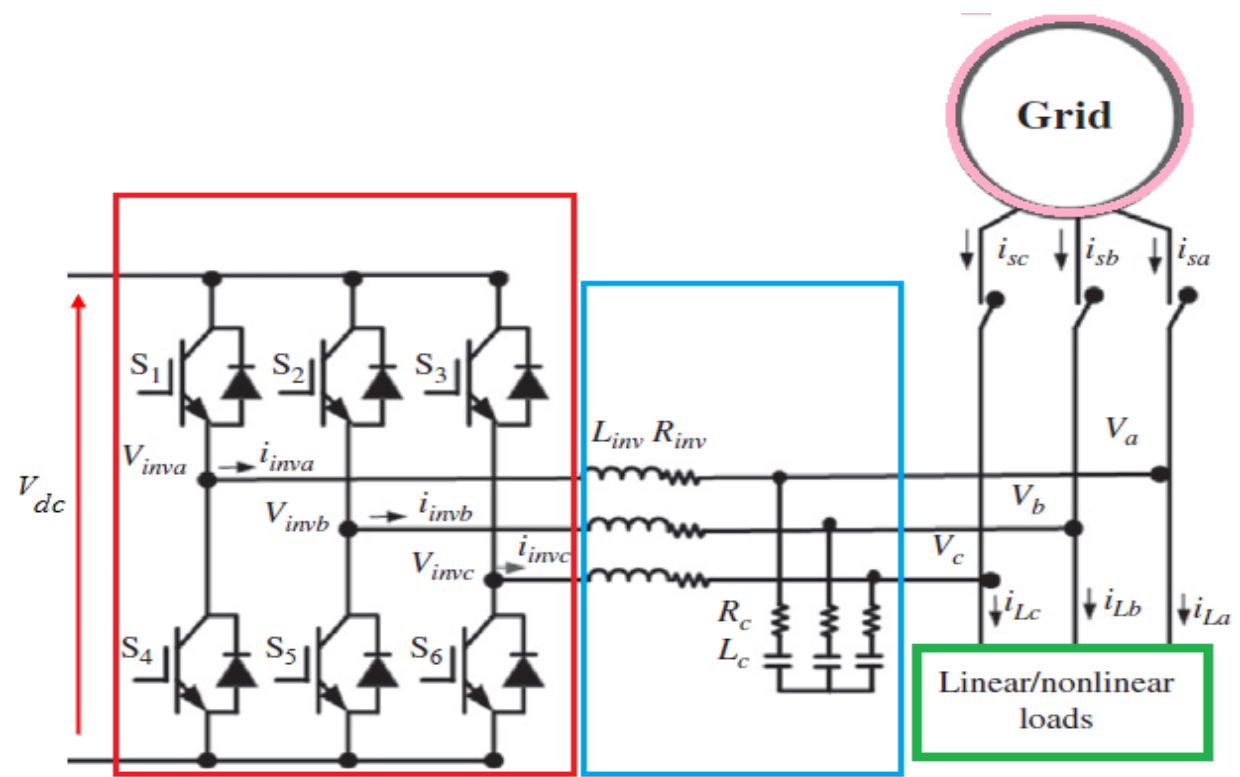

Figure. 5 Block diagram of three-phase DC/AC Voltage source inverter and grid

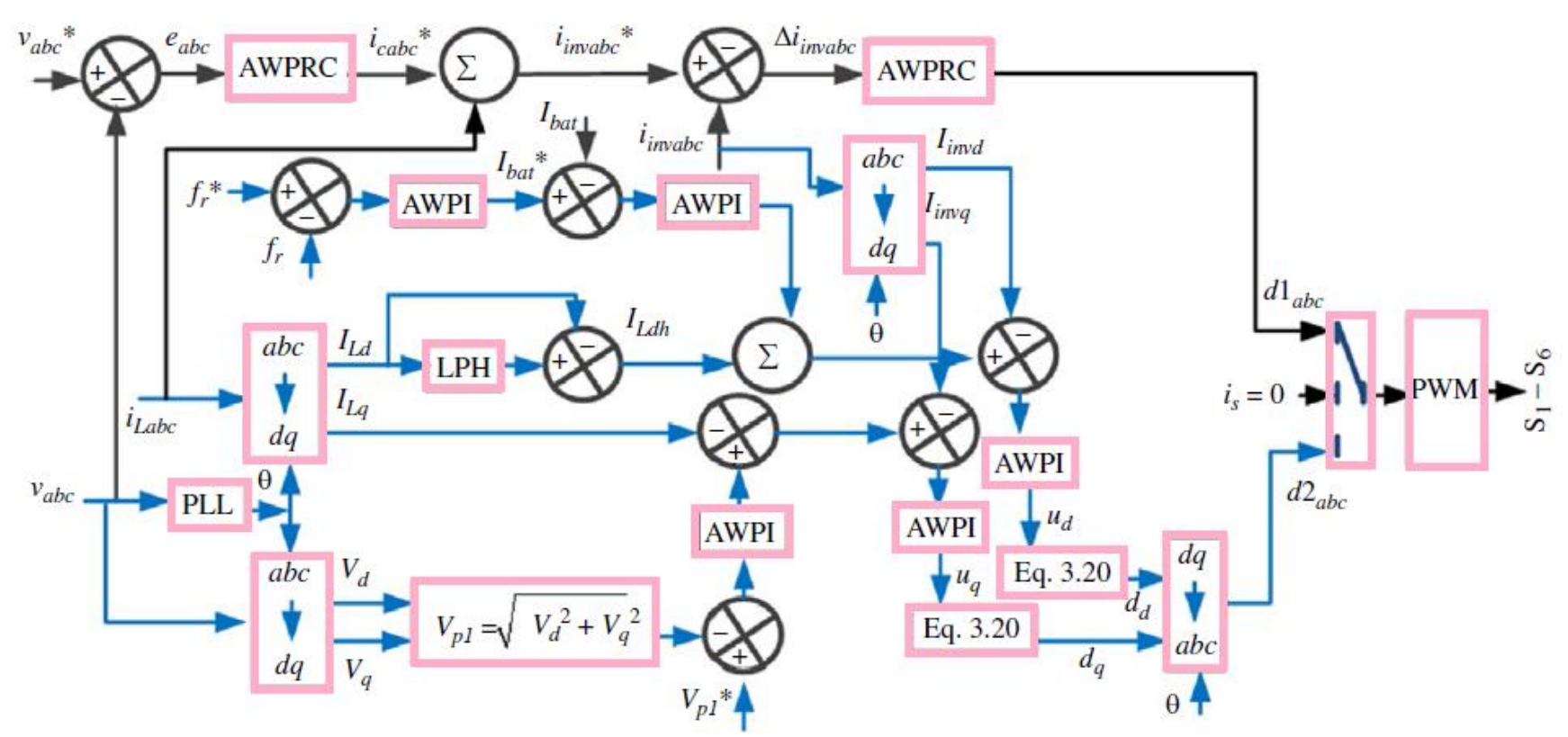

Figure. 6 Contol technique for three-phase DC/AC voltage source inverter and grid 
The first step is the elaborate control technique presented in Fig. 6 to choose the duty cycles $\left(d_{1 a b c}\right)$ obtained via point of common coupling (PPC) voltages as:

$$
\left\{\begin{array}{c}
v_{a}^{*}=V_{P 1} \sin \left(\omega_{s} t\right) \\
v_{b}^{*}=V_{P 1} \sin \left(\omega_{s} t-2 \pi / 3\right) \\
v_{c}^{*}=V_{P 1} \sin \left(\omega_{s} t+2 \pi / 3\right)
\end{array}\right.
$$

Where: $\omega_{s}=2 \pi f_{s}$

We obtained the references currents $i_{\text {inv }(a b c)^{*}}$ of the inverter by via outputs of outer loops, that represent the references currents of the RC passive filter also, $\left(i_{L(a b c)}\right)$ presents the load currents:

$$
i_{\text {inv }}=i_{C(a b c)}^{*}+i_{L(a b c)}
$$

The strategy control compared the references current of the inverter with measured currents $\left(i_{i n v(a b c)}\right)$ of the inverter, the errors are injected to AWPRC and the outputs control signals $\left(d_{1 a}, d_{1 b}\right.$ and $\left.d_{1 c}\right)$ are injected to PWM generator to generate pulses for the three-phase VSI. The second level of control strategy shown in Fig.6, seasonable the duty cycles $\left(d_{d q}\right)$ a phased locked loop (PLL) is designed to estimate the frequency and to synchronize the three-phase VSI with PCC. The AWPI voltage regulator is subtracted the reactive component of the load current. We estimate the active and reactive elements of source currents via Park's transformation. The measured VSC and Sensed three-phase load currents converted to d-q-equivalent. We fed the errors between $\mathrm{d}-\mathrm{q}$ axis VSI currents $\left(d_{\text {dinv }}\right.$ and $\left.d_{\text {qinv }}\right)$ and load to AWPI current controllers $\left(d_{d}\right.$ and $\left.d_{q}\right)$. We obtain the duty cycle $\left(d_{2 a b c}\right)$ via inverse Park transformation, the latter that fed to PWM to generate the switching pulses to VSI.

$$
\left\{\begin{array}{l}
d_{d}=\frac{-u_{d}+v_{d}+L_{f} \omega_{s} i_{d i n v}}{V_{d c}} \\
d_{d}=\frac{-u_{d}+v_{q}-L_{f} \omega_{s} i_{q i n v}}{V_{d c}}
\end{array}\right.
$$

\section{Batteries energy storage system with management}

We propose the Battery Energy Storage System connected in the same time to PV and grid as illustrate in Fig.7. This part of system continent batteries connected to one common DC bus via BuckBoost converter with control strategy [33, 34].

We add the Battery Energy Storage System with a controller to save the DC bus voltage at the desired value determined via MPTT controller with the principle present in Fig. 8. We stable the DC reference voltage $V_{d c_{r e f}}$ at $500 \mathrm{~V}$ via the PI corrector calculates the reference current of DC bus $I_{d c_{r e f}}$. We produce the reference current $I_{d c_{r e f}}$ also reference current of batteries $I_{b a t_{r e f}}$ of the DC bus which is determined by the DC bus control loop.

The batteries combined with an energy control; the control algorithm shown in Fig.9. The state of charge of batteries in our PV system $S o C_{b a t}$ should be between [25\% and $95 \%$ ]. The $I_{b a t_{r e f}}$ batteries reference current constructed based on the passage of the reference current of DC bus $I_{d c_{r e f}}$ from a lowpass filter.

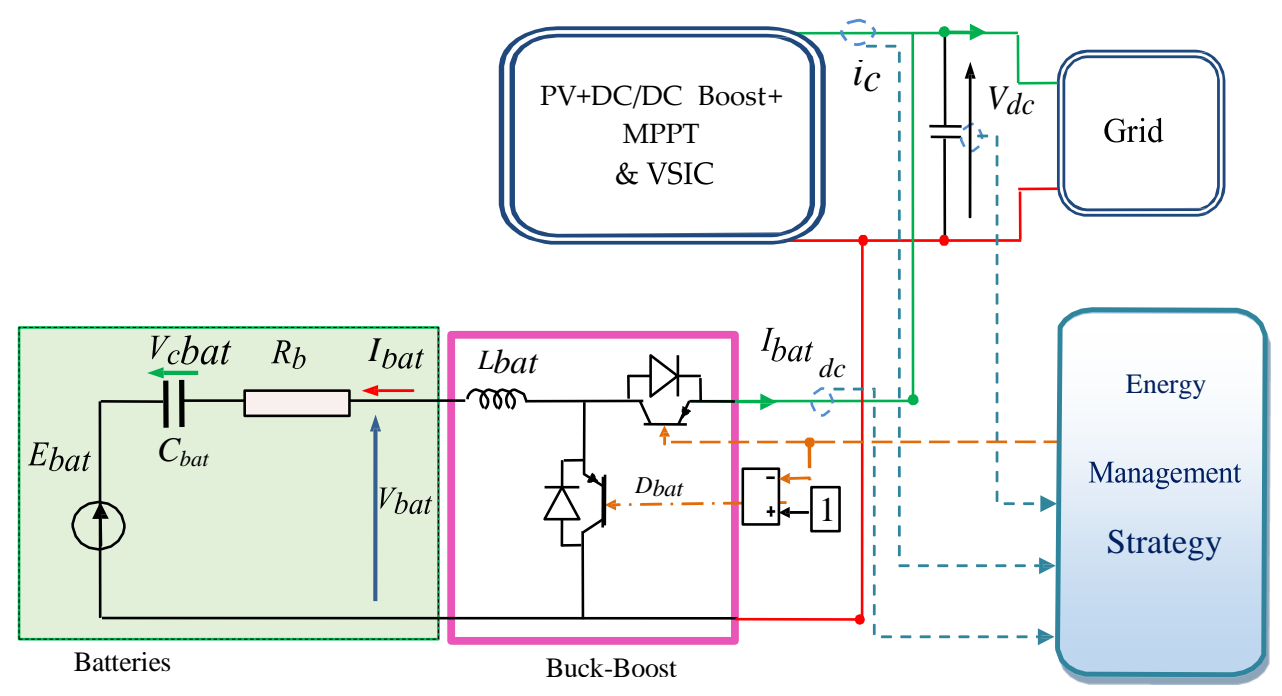

Figure. 7 Batteries energy storage system 


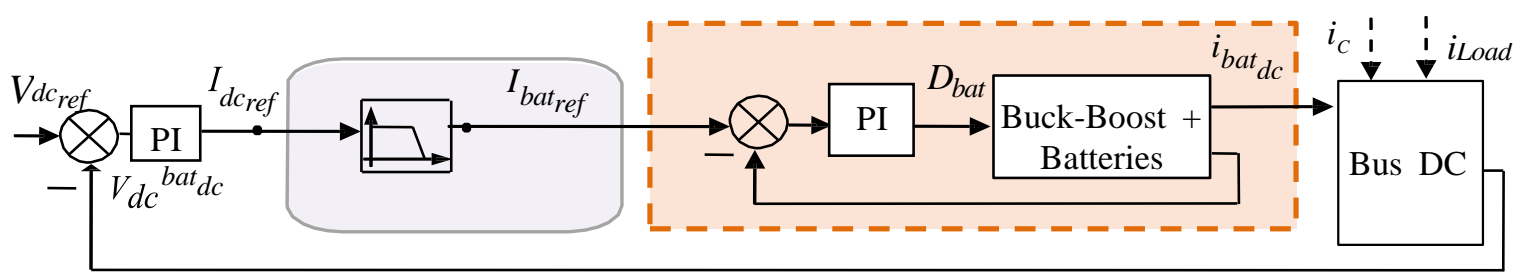

Figure. 8 Control the DC bus voltage

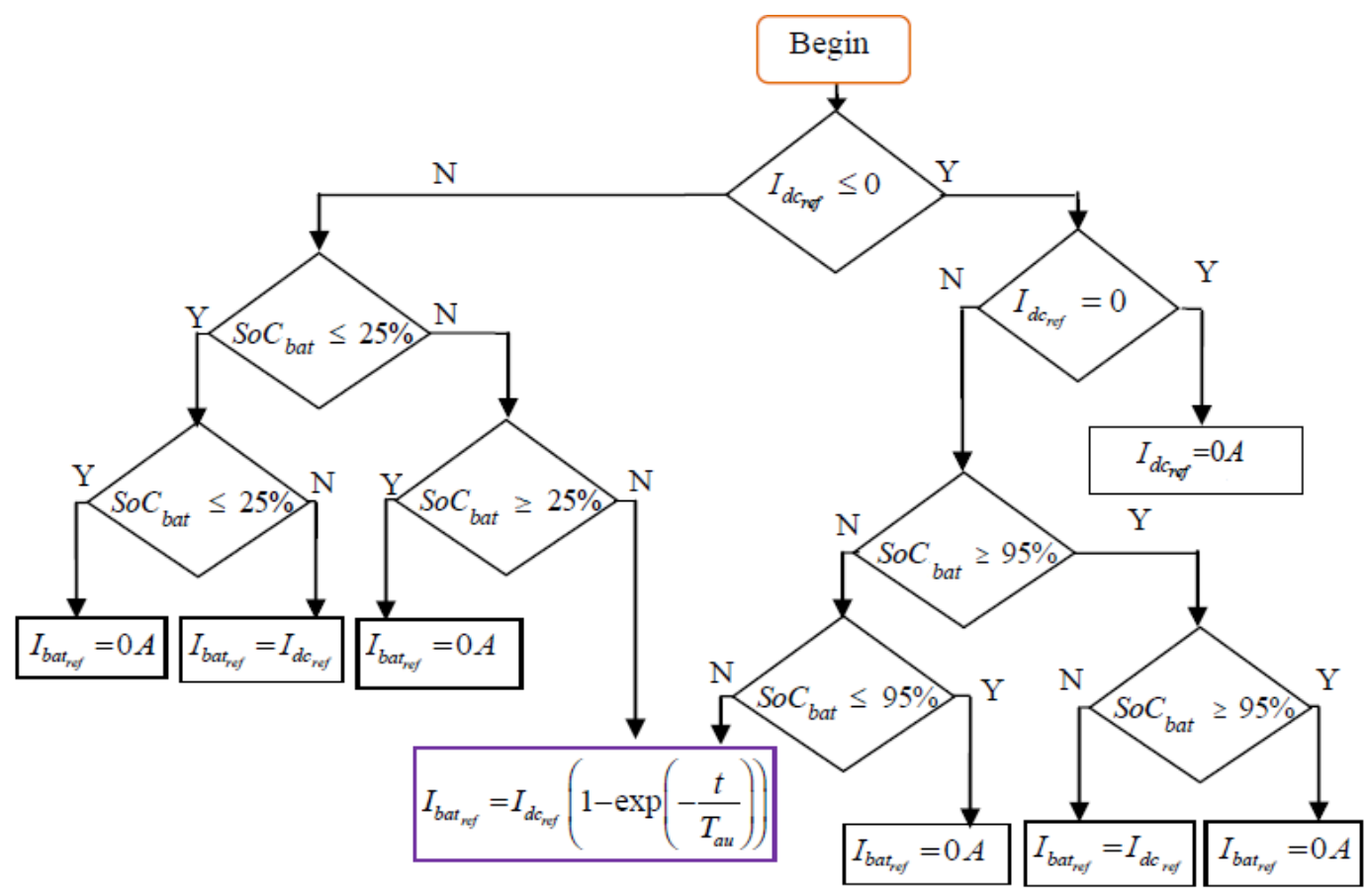

Figure. 9 Control algorithm of storage energy in the batteries

\section{MPPT controller design}

The target of this controller is to extract the MPPT from the PV. We designed the nonlinear Fuzzy Logic-Integral Backstepping to control the duty cycle of the full action generate via climatic conditions. We introduced the boost converter switch to improve the robust properties of the Fuzzy LogicIntegral Backstepping.

We used the Fuzzy logic to obtaine the reference voltge and we designed the Integral Backstepping recursive controller for nonlinear systems as strict feedback, based on Lyapunov functions. The general principle concept of the Integral Backstepping is to treat the system variable as an independent entry for subsystems and individual stage results of a new virtual controller to the next step. The virtual control law for any step realized with satisfaction functions

Lyapounov chosen so that the stability of each subsystem. The design of the control achieved in towing steps.

$y=\partial p / \partial v_{p}$. The control objective is to solve the tracking problem. $\lim _{t \rightarrow \infty}\left(y(t)-y_{d}(t)\right)=0$

Where $y_{d}=V_{P V r-e f}$ : The reference voltage

\section{- Backstepping design :}

Step1: We define:The error, $\varepsilon_{1}=y-y_{d}$ also the Integral action $\varphi(t)=\int_{0}^{t}\left(y(\tau)-y_{d}(\tau)\right) d \tau$ to make the system more dynamic and decrease the response time.

The first subsystem feedback:

$$
\left\{\begin{array}{c}
\dot{\varphi}=\varepsilon_{1} \\
\dot{\varepsilon}_{1}=\frac{1}{C_{p}}\left(2 \frac{\partial i}{\partial v_{p}}+v_{p} \frac{\partial^{2} i}{v_{p}^{2}}\right)\left(i-i_{L}\right)-\dot{V}_{P V-r e f}
\end{array}\right.
$$

We take the inductor current $i_{L}$ as a signal of control for Eq. (10) and determining the first positive Lyapunov function:

$$
V_{1}\left(\varepsilon_{1}, \varphi\right)=\frac{1}{2} \varepsilon_{1}^{2}+\frac{1}{2} \varphi^{2}
$$


The solution of (8) computed via the time derivative of $V_{1}$ :

$\dot{V}_{1}=\varepsilon_{1}\left[\varphi+\frac{1}{C_{p}}\left(2 \frac{\partial i}{\partial v_{p}}+v_{p} \frac{\partial^{2} i}{\partial v_{p}^{2}}\right)\left(i-i_{L}\right)-\dot{V}_{P V-r e f}\right]$

We can obtain the stabilization of $\varepsilon_{1}$ and $\varphi$ by introducing a new virtual control $\alpha_{1}=\left(i_{L}\right)_{d}$,

Where: $\left(i_{L}\right)_{d}$ is the desire value of the inductor current.

The virtual control law expressed:

$$
\begin{aligned}
\varphi & +\frac{1}{C_{P}}\left(2 \frac{\partial i}{\partial v_{p}}+v_{p} \frac{\partial^{2} i}{\partial v_{p}^{2}}\right)(i-\alpha)-\dot{V}_{P V-r e f} \\
& =-K_{1} \varepsilon_{1}
\end{aligned}
$$

Where $K_{1}$ is constant $K_{1}>0$ :

$$
\alpha_{1}=i+\frac{C_{p}}{2 \frac{\partial i}{\partial v_{p}}+v_{p} \frac{\partial^{2} i}{\partial v_{p}^{2}}}\left(K_{1} \varepsilon_{1}+\varphi-\dot{V}_{P V-r e f}\right)
$$

The time derivative of $\dot{V}_{1}$ becomes:

$$
\dot{V}_{1}=-K_{1} \varepsilon_{1}^{2}<0
$$

Step 2: We propose the error variable therefore, we consider the virtual controller as a preference. The behaviour of the inductor current error:

$$
\varepsilon_{2}=i_{L}-\alpha_{1}
$$

Where the inductor current should take the value of $\alpha_{1}$ to push the error vanishes in order to achieve the target of control. The error time derivative is:

$$
\dot{\varepsilon}_{2}=\frac{d i_{L}}{d t}-\dot{\alpha}_{1}=\frac{1}{L}\left(v_{p}-(1-\mu) V_{d c}\right)-\dot{\alpha}_{1}
$$

Substituting $i_{L}=\varepsilon_{2}-\alpha_{1}$ into Eq. (8), $\dot{\varepsilon}_{1}$ becomes:

$$
\begin{aligned}
\dot{\varepsilon}_{1}= & \frac{1}{C_{p}}\left(2 \frac{\partial i}{\partial v_{p}}+v_{p} \frac{\partial^{2} i}{\partial v_{p}^{2}}\right)\left(i-\varepsilon_{2}-\alpha_{1}\right) \\
& -\dot{V}_{P V-r e f}
\end{aligned}
$$

Introducing (11); we obtain the time derivative of $\varepsilon_{1}$ and $V_{1}$ :

$$
\dot{\varepsilon}_{1}=-K_{1} \varepsilon_{1}-\varphi-\frac{1}{C_{p}}\left(2 \frac{\partial i}{\partial v_{p}}+v_{p} \frac{\partial^{2} i}{\partial v_{p}^{2}}\right) \varepsilon_{2}
$$

$$
\dot{V}_{1}=-K_{1} \varepsilon_{1}^{2}-\frac{1}{C_{P}}\left(2 \frac{\partial i}{\partial v_{p}}+v_{p} \frac{\partial^{2} i}{\partial v_{p}^{2}}\right) \varepsilon_{1} \varepsilon_{2}
$$

Now, we give the time derivative of $\alpha_{1}$ by:

$$
\begin{aligned}
\dot{\alpha}_{1}=\left[\frac{\partial i}{\partial v_{p}} \frac{\partial v_{p}}{\partial t}+C_{p}\left[\frac{\left(K_{1} \dot{\varepsilon}_{1}+\varepsilon_{1}\right)}{\left(2 \frac{\partial i}{\partial v_{p}}+v_{p} \frac{\partial^{2} i}{\partial v_{p}^{2}}\right)}-\frac{\left(K_{1} \varepsilon_{1}+\varphi\right)}{\left(2 \frac{\partial i}{\partial v_{p}}+v_{p} \frac{\partial^{2} i}{\partial v_{p}^{2}}\right)^{2}}\right.\right. \\
\left.\left.\left(3 \frac{\partial^{2} i}{\partial v_{p}^{2}}+v_{p} \frac{\partial^{3} i}{\partial v_{p}^{3}}\right) \frac{\partial v_{p}}{\partial t}\right]\right]
\end{aligned}
$$

Considering the final Lyapunov function candidate:

$$
V_{2}\left(\varphi, \varepsilon_{1}, \varepsilon_{2}\right)=V_{1}+\frac{1}{2} \varepsilon_{2}^{2}
$$

The time derivative of this function is:

$$
\begin{gathered}
\dot{V}_{2}\left(\varphi, \varepsilon_{1}, \varepsilon_{2}\right)=V_{1}+\varepsilon_{2} \dot{\varepsilon}_{2} \\
\dot{V}_{2}=-K_{1} \varepsilon_{1}^{2}+\varepsilon_{2}\left[-\frac{1}{C_{p}}\left(2 \frac{\partial i}{\partial v_{p}}+v_{p} \frac{\partial^{2} i}{\partial v_{p}^{2}}\right) \varepsilon_{1}\right. \\
\left.+\frac{1}{L}\left(v_{p}-V_{d c}\right)+\frac{1}{L} \mu V_{d c}-\dot{\alpha}_{1}\right]
\end{gathered}
$$

$$
\begin{aligned}
\mu=\frac{1}{V_{d c}}\left[-K_{2} \varepsilon_{2}\right. & +\frac{1}{C_{p}}\left(2 \frac{\partial i}{\partial v_{p}}+v_{p} \frac{\partial^{2} i}{\partial v_{p}^{2}}\right) \varepsilon_{1} \\
& \left.-\frac{1}{L}\left(v_{p}-V_{d c}\right)+\dot{\alpha}_{1}\right]
\end{aligned}
$$

Where $k_{2}>0$ is a positive constant:

The above choice yields:

$$
\dot{V}_{2}=-K_{1} \varepsilon_{1}^{2}-K_{2} \varepsilon_{2}^{2}<0
$$

We obtain the vector error: $\varepsilon=\left(\varepsilon_{1}, \varepsilon_{2}\right)$ converges asymptotically to the origin: $\varepsilon_{1}=y-y_{d}=\partial p / \partial v$ track the asymptotic originally the control target. Then the PV power generator followed by the MPPT, automatically, we realize the stability. As a result, we ensured the control system.

\section{- Generation of voltage reference estimator via Fuzzy Logic Controller}

We use the fuzzy logic controller (FLC) commonly to obtain the MPP [35]. Because it identifies, resolves the problem of nonlinearity and gives a robust performance respecting the weather changes. The FLC observe the PV value characteristics voltage and current then changes with climatic conditions temperature and irradiation to calculate the reference voltage $\left(V_{P V-r e f}\right)$ and 


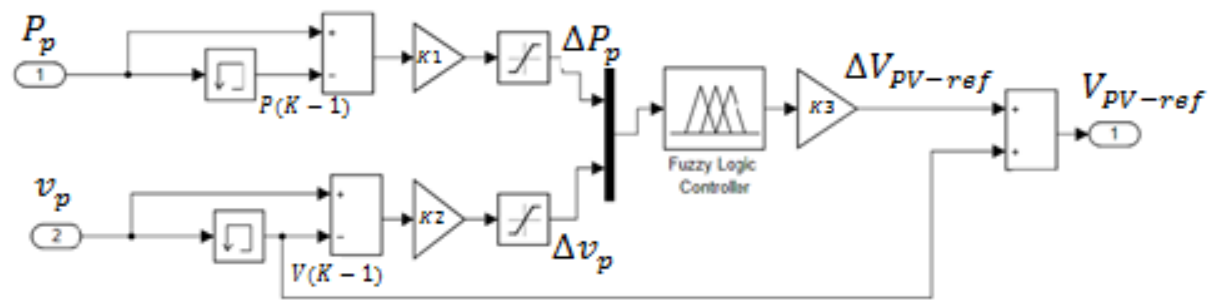

Figure. 10 Structure of fuzzy controller

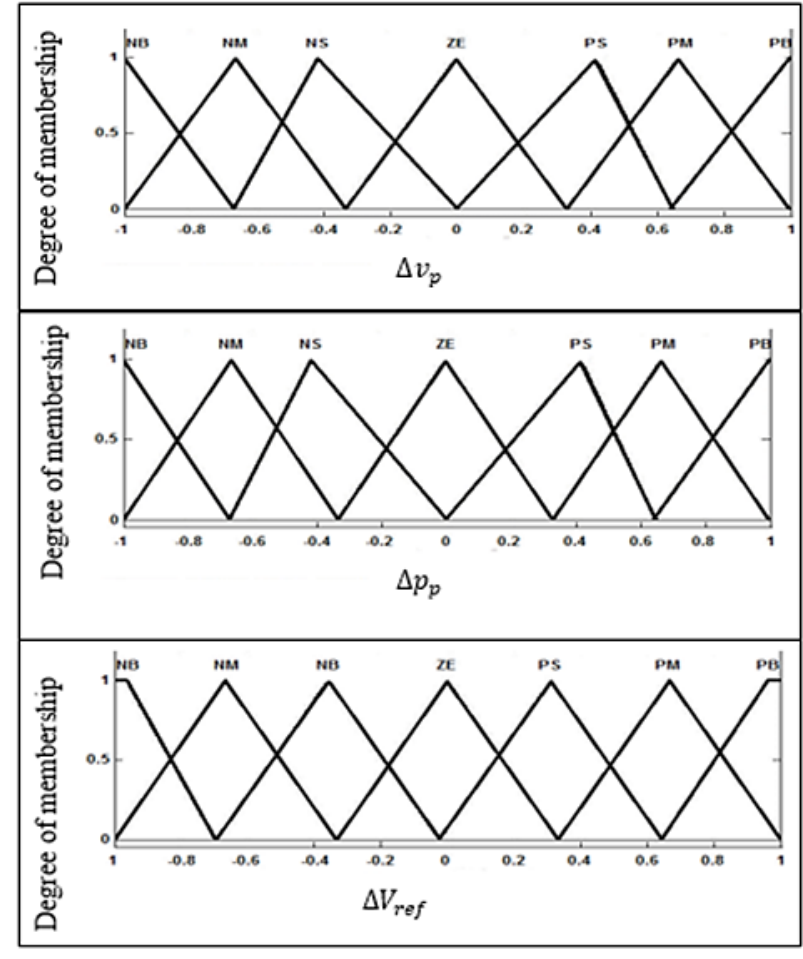

Figure. $11 \Delta V_{P V-r e f}, \Delta v_{p}, \Delta P_{p}$ : Memberships functions

resulting $\mathrm{PV}$ power variation $\left(\Delta P_{p}\right) . \Delta P_{p}$ takes positive or negative values. To design a good inferences base of FLC, we add the photovoltaic voltage variation $\left(\Delta v_{p}\right)$ and reference voltage variation $\left(\Delta V_{P V-r e f}\right)$ is upgraded or downgraded in the direction which might escalate the power $P_{p}$.

We mentioned the control rules of FLC to calculate the $V_{P V-r e f}$ in a (Table 1) with $\left(\Delta P_{p}\right)$ and $\left(\Delta v_{p}\right)$ as inputs, while $\left(\Delta V_{P V-r e f}\right)$ is the output. The inputs and output variables are linguistically expressed (as NB: Negative Big, NM: Negative Medium, NS: Negative Small, ZE: Zero, PS: Positive Small, PM: Positive Medium, PB: Positive Big). The FLC mentioned the reference voltage $\left(\Delta V_{P V-r e f}\right)$ in Eq. (26) via linking between the Eqs. (23) and (25).

$$
\begin{aligned}
\Delta P_{p} & =P_{p}(k)-P_{p}(k-1) \\
\Delta v_{p} & =v_{p}(k)-v_{p}(k-1) \\
V_{P V-r e f}(k) & =v_{p}(k-1)-\Delta V_{P V-r e f}(k-1)
\end{aligned}
$$

Table 1. Control Rules Base for $V_{P V-r e f}$ Fuzzy Controller

\begin{tabular}{|l|l|l|l|l|l|l|l|}
\hline$V_{p} / P_{p}$ & NB & NM & NS & ZE & PS & PM & PB \\
\hline NB & ZE & ZE & ZE & NB & NB & NB & NB \\
\hline NM & ZE & ZE & ZE & NM & NM & NM & NM \\
\hline NS & NS & ZE & ZE & NS & NS & NS & NS \\
\hline ZE & NM & NS & ZE & ZE & ZE & PS & PM \\
\hline PS & PM & PS & PS & PS & ZE & ZE & ZE \\
\hline PM & PM & PM & PM & PM & ZE & ZE & ZE \\
\hline PB & PB & PB & PB & PB & ZE & ZE & ZE \\
\hline
\end{tabular}

Where: The photovoltaic generator characteristics values at a spontaneous lapse of times, the power $P_{p}(k)$ and the voltage $v_{p}(k) . V_{P V-r e f}(k)$ the instant of the voltage reference. The FLC structure is shown in Fig.10. The FLC block based on three functional sub-blocks: Fuzzification, Fuzzy rules algorithm, and Defuzzification. Fig. 11 gives the membership functions of variables of inputs $\Delta v_{p}$ and $\Delta P_{p}$ also, the output variable $\Delta V_{P V-r e f}$ the Inputs/Outputs are shaped in triangular forms and have 7 fuzzy subsets. The fuzzy inference chosen output by using Mamdani's method, and the defuzzification based on the gravity center to compute the output of this FLC.

\section{Results and discussions}

Our study dedicated to the PV connected storage system and grid. We realize the major aims of this work: We obtain the maximum power from panel and stability the DC/DC boost output voltage via Fuzzy Logic-Integral Backstepping. Next, we added the Batteries energy storage system with management to keep the power at a stable level in the grid. In addition, we designed a VSIC to keep grid parameters at the desired values. We simulated our system in the MATLAB/SIMULINK environment. We mentioned all the values of the principal components used in our PV system in the tables:

- We filtrate the harmonics produced by VSC via10-kvar capacitor bank.

- The transformer three-phase coupling 100kVA $260 \mathrm{~V} / 25 \mathrm{kV}$.

- The grid utility: Distribution 25-kV

- + Equivalent transmission system $120 \mathrm{kV}$. 
Table 2. PV 330 * SunPower SPR-305E-WHT-D values

\begin{tabular}{|l|c|}
\hline \multicolumn{1}{|c|}{ Component } & Input data value \\
\hline$N_{S}$ & 66 \\
\hline$E_{G 0}$ & 1.12 \\
\hline$K$ & $1,3805.10^{-23} \mathrm{~J} / \mathrm{K}^{\circ}$ \\
\hline$q$ & $1,6201.10^{-19} \mathrm{C}$ \\
\hline$R_{S}$ & $153.2529 \mathrm{Ohms}$ \\
\hline$R_{S h}$ & $0.44959 \mathrm{Ohms}$ \\
\hline$\gamma$ & 1.4 \\
\hline
\end{tabular}

Table 3. DC/DC boost

\begin{tabular}{|l|c|}
\hline Component & Input data value \\
\hline$C_{P}$ & $47.10^{-3} \mathrm{~F}$ \\
\hline$C_{m}$ & $4.7 .10^{-3} \mathrm{~F}$ \\
\hline$L$ & $3.5 .10^{-3} \mathrm{H}$ \\
\hline
\end{tabular}

Table 4. Characteristics of the energy storage system

\begin{tabular}{|c|c|}
\hline Component & \multicolumn{1}{|c|}{ Input data value } \\
\hline $\begin{array}{c}\text { Maximal Power } \\
\text { of batteries charge }\end{array}$ & $48 \mathrm{~kW}$ \\
\hline $\begin{array}{c}\text { Switching } \\
\text { frequency }\end{array}$ & $5000 \mathrm{kHz}$ \\
\hline Bus DC & $V_{d c}=500 \mathrm{~V}$ \\
& $k_{i_{d c}}=0.36$ \\
& $k_{P_{d c}}=0.0025$ \\
\hline Batteries, Buck- & $C_{\text {buck_boost_out }}=5,4.10^{-3} \mathrm{~F}$ \\
Boost and PI & $L_{\text {buck_boost }}=15.10^{-3} \mathrm{H}$ \\
controller & $K_{i_{\text {bat }}}=8.3$ \\
& $K_{P_{\text {bat }}}=0.037$ \\
& $L_{\text {bat }}=15.10^{-3} \mathrm{H}$ \\
\hline
\end{tabular}

Table 5. Integral backstepping controller gains values

\begin{tabular}{|c|c|}
\hline Component & Input data value \\
\hline$K_{1}$ & 15000 \\
\hline$K_{2}$ & 200000 \\
\hline
\end{tabular}

To verify the success of the quality and efficiency of the controllers in the PV system. We chose to test the controller's performances under variable climatic conditions solar irradiation and temperature given in Fig. 12, we change the irradiation of the PV from $1000 \mathrm{~W} / \mathrm{m} 2$ until $\mathrm{t}=6 \mathrm{~s}$. Then the irradiation dropped to $600 \mathrm{~W} / \mathrm{m}^{2}$. After $14 \mathrm{~S}$, the irradiation is up to 1000 $\mathrm{W} / \mathrm{m}^{2}$. In parallel, the temperature maintained at $25^{\circ} \mathrm{C}$, between 0 s and $10 \mathrm{~s}$ and rises from $25^{\circ} \mathrm{C}$ to $50{ }^{\circ} \mathrm{C}$ until the end of the simulation.

Fig. 13 shows the output voltage, current and power curves of the PV panel. We notice that the parameters generate provided by the PV varies with the intensity of irradiation and the temperature of the climatic conditions. Fig.14 presents the batteries state of charge and discharge (SOC in \%) with climatic conditions, Fig.15. and Fig.16 shows successively the batteries power response between compensation and energy-storage in the PV system and current variation of the batteries pending the charge and discharge with PV system. The results prove the success of the add a batteries-energy-storage system with management on the DC side to compensate for power fluctuation and current in the system.

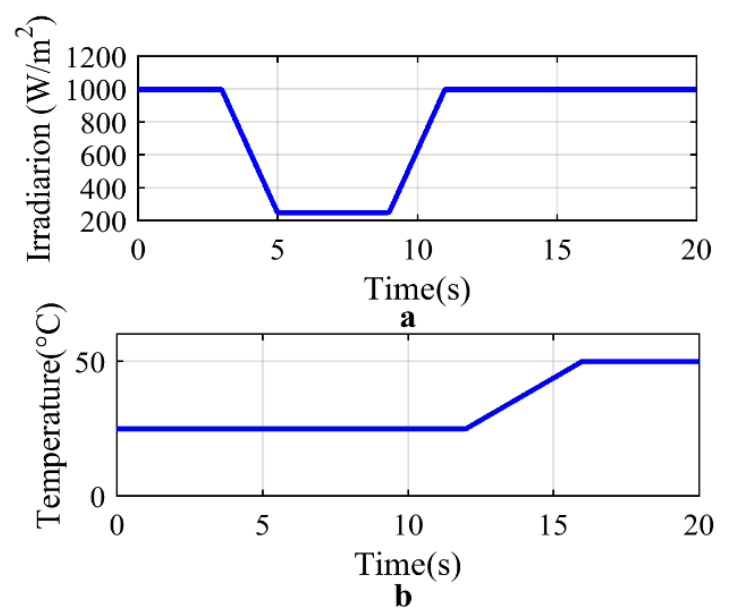

Figure. 12 Change of the weather condition curves: (a) solar irradiation and (b) temperature

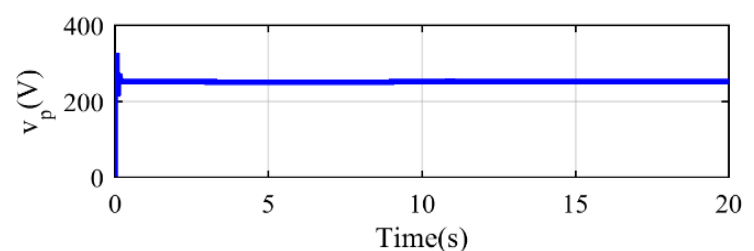

(a)

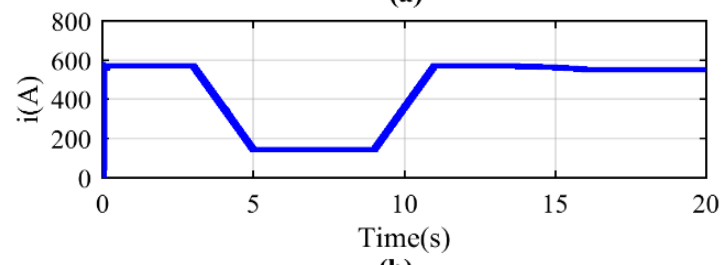

(b)

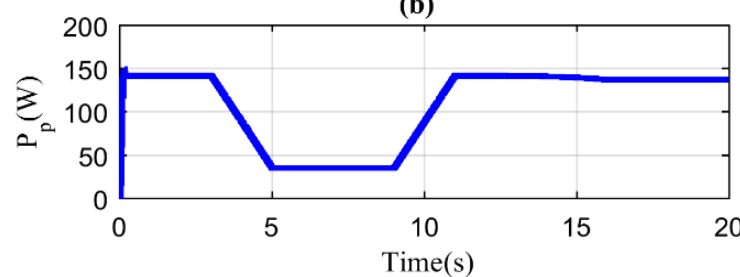

(c)

Figure. 13 PV output: (a) voltage, (b) current, and (c) power

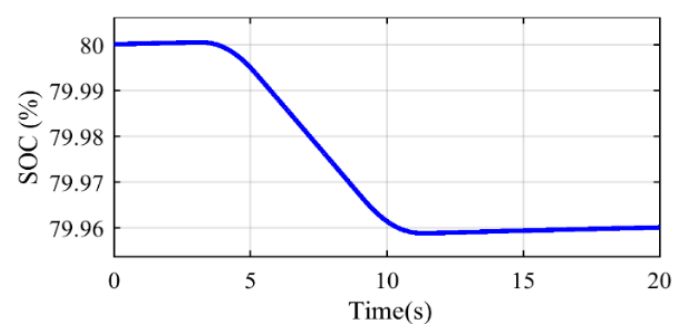

Figure. 14 The battery's SOC response with PV system 


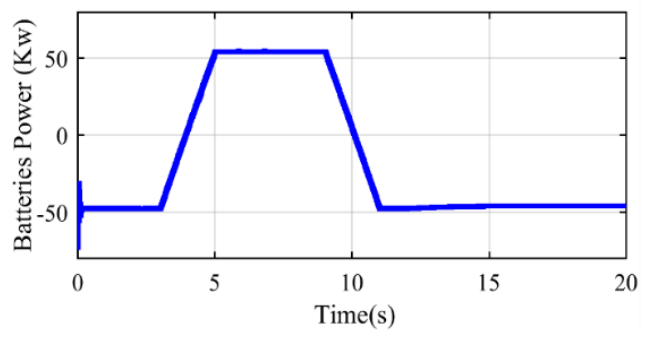

Figure. 15 The batteries's power response with PV system

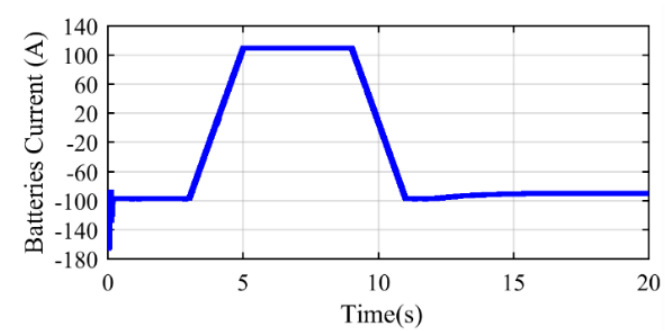

Figure. 16 The batteries's current response with PV system

Fig. 17 present the estimator of reference voltage generates via Fuzzy logic controller Therefore, Fig. 18 shows the stable output voltage of DC/DC boost at $500 \mathrm{~V}$ also the duty cycle signal. As a result, we obtained the maximum voltage from the PV that give automatically the maximum power point of the photovoltaic generator, after a transition-response relying on sunlight and temperature changes for the PV. We observe that the MPPT algorithm by using Fuzzy logic-Integral Backstepping which gives excellent results because the FLC gives a better dynamic and robustness. Afterward, the Integral Backstepping gives the stability system via the Lyapunov theory and integral action. In general, we notice that the controller evaluated the efficiency of the system, gives a good performance and robustness also, has an exact following effect at the desired values in each part of the PV system.

Figs. 19 and 20 indicated 3-phase of voltage in the grid and its zoom, Fig. 21 and Fig. 22 indicated 3 -phase current in the grid, and its zoom, Fig. 23 shows the single-phase voltage and the single-phase voltage current in the grid we notice that the two parameters are in phase. Fig. 24 presents the power of the grid stay stable at $98 \mathrm{~kW}$ controlled by VISC. It is worth noting that the performance kept at the wished values, no matter what the values of solar irradiance and temperature conditions. By doing so we make sure, we have a stable operation of the PV connected grid system with Fuzzy Logic-Integral Backstepping and battery energy storage system. Furthermore, the VSIC gives satisfactory results on the grid side for voltage, current and, frequency.
As general, results, we realized the target of the work, as discussed: We designed a PV system connected grid and energy storage system with stable parameters (power, voltage, current and, frequency) on the grid side. These results obtained via three best controllers: Fuzzy logic-Integral Backstepping to obtain MPPT from PV, the add of Batteries Energy Storage System management to manage the energy obtained between the grid and the injection energy in the grid via, the VSIC. The aim of work presents a successful PV system with high performance with all climatic conditions.

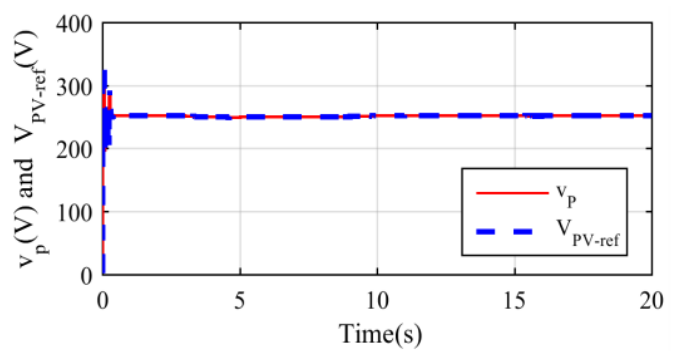

Figure. 17 PV voltage and PV reference voltage

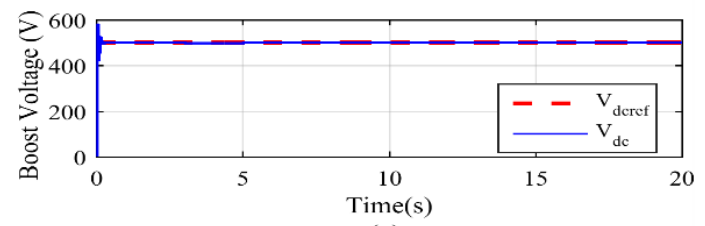

(a)

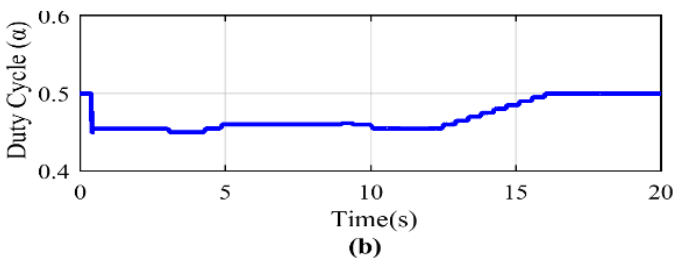

Figure. 18 (a) Bus voltage and (b) boost duty cycle

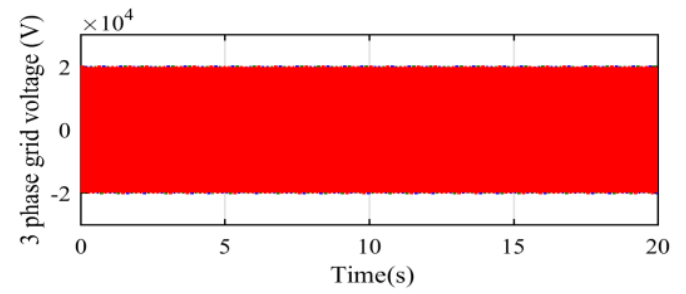

Figure. 19 3-phase voltage grid

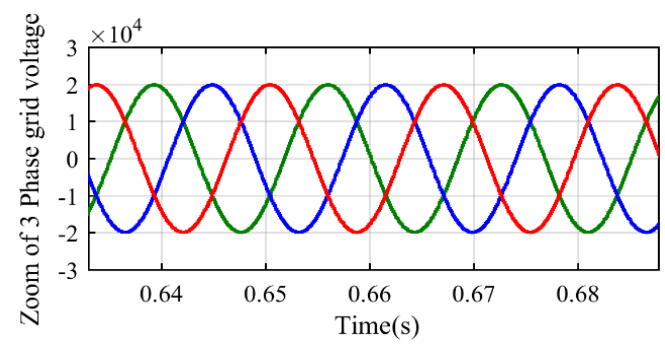

Figure. 20 Zoom of 3 Phase voltage 


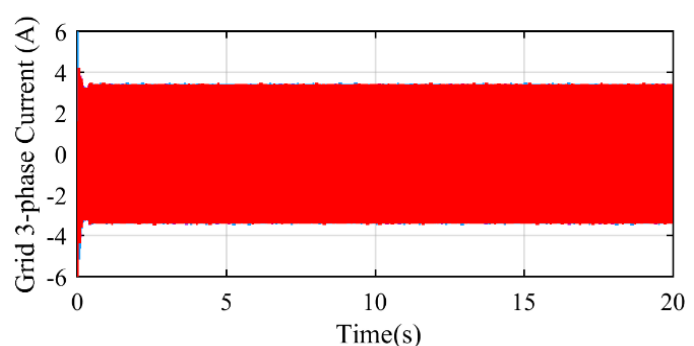

Figure. 21 3-phase current grid

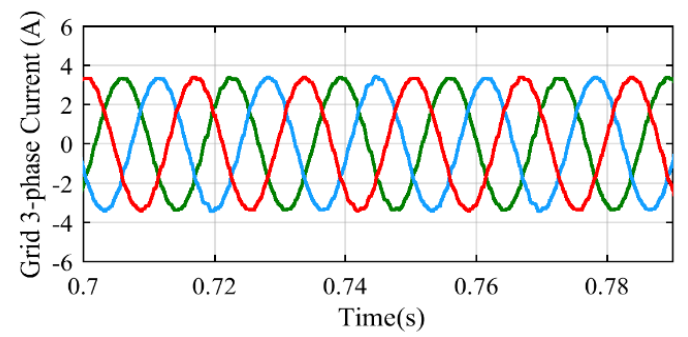

Figure. 22 Zoom of 3-Phase current grid

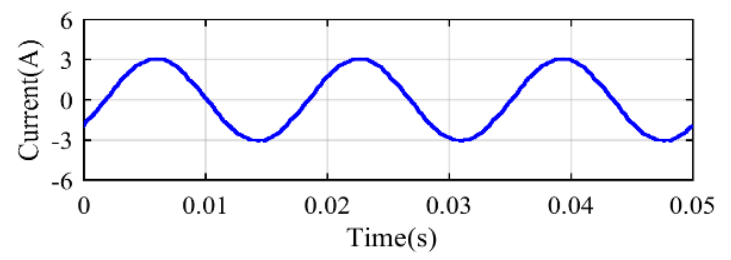

(a)

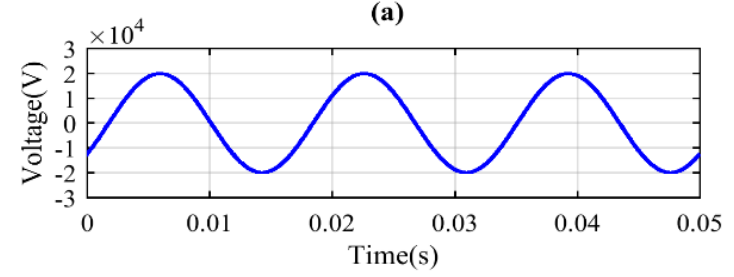

(b)

Figure. 23 One phase: (a) gid voltage and (b) grid current

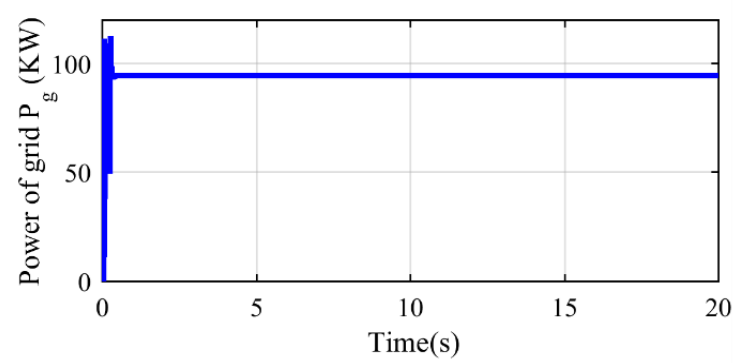

Figure. 24 Grid power

\section{Conclusion}

The PV system connected the grid with batteries energy storage system studied under different values of irradiation and temperature, which is the major influence on the PV system. Its give the fluctuation in power and destabilized the tension. When we identifying an MPPT controller based on Fuzzy Logic-Integral Backstepping to give the system, high performance and, good efficiency during operation.
The MPPT used a synthesized strategy focus on the Fuzzy Logic-Integral Backstepping controller. The global target-present to obtain a rapid response, stability, and, robustness determined by the Lyapunov theory. In addition, the batteries energy storage system with management as a regulator of energy generated via PV because it saves the power in the constant value all the time via compensation for lack of power/absorption of excess power in the grid. Also, the use of the VSIC controller makes the grid current, voltage, and frequency at a good value and balanced in 3-phases also make the currents and the voltages in phases in the grid.

This study gives a good solution to the stability and management of energy. Also, it gives a lot of possibilities to integrate this system into a smart grid with different energy sources.

\section{References}

[1] R. Teodorescu, M. Liserre, and P. Rodrłguez, Grid converters for photovoltaic and wind power systems, Wiley, New York, 2011.

[2] M. Yesilbudak, M. Colak, and R. Bayindir, "What are the Current Status and Future Prospects in Solar Irradiance and Solar Power Forecasting?", International Journal of Renewable Energy Research, Vol. 8, pp. 636-646, 2018.

[3] J. M. Carrasco, L. G. Franquelo, and J. T. Bialasiewicz, "Power-electronic systems for the grid integration of renewable energy sources: a survey", IEEE Transactions on Industrial Electronics, Vol. 53, pp. 1002-1016, 2006.

[4] R. Deshpande, "Analysis of Power Quality Variations in Electrical Distribution System with Renewable Energy Sources", International Journal of Renewable Energy Research, Vol. 9, pp. 282-289, 2019.

[5] J. Liu, W. Luo, and X. Yang, "Robust modelbased fault diagnosis for PEM fuel cell air-feed system", IEEE Transactions on Industrial Electronics, Vol. 63, pp. 3261-3270, 2016.

[6] Y. Yang, Q. Ye, and L. Tung, "Integrated size and energy management design of battery storage to enhance grid integration of large-scale PV power plants", IEEE Transactions on Industrial Electronics, Vol. 65, pp. 394-402, 2018.

[7] A. Kouchaki, H. Iman-Eini, and B. Asaei, "A new maximum power point tracking strategy for PV arrays under uniform and non-uniform insolation conditions", Solar Energy, Vol. 91, pp. 221-232, 2013.

[8] M. H. Moradi and A. R. Reisi, "A hybrid maximum power point tracking method for 
photovoltaic systems", Solar Energy, Vol. 85, pp. 2965-2976, 2011.

[9] D. Xua, G. Wanga, W. Yana, and X. Yanb, “A novel adaptive command-filtered backstepping sliding mode control for PV grid-connected system with energy storage", Solar Energy, pp. $1-17,2019$.

[10] M. B. Delghavi and A. Yazdani, "Islanded-mode control of electronically coupled distributedresource units under unbalanced and nonlinear load conditions", IEEE Transactions on Power Delivery, Vol. 26, pp. 661-673, 2011.

[11] S. Ouchen, S. Abdeddaim, A. Betka, and A. Menadi, "Experimental validation of sliding mode-predictive direct power control of a gridconnected photovoltaic system, feeding a nonlinear load", Solar Energy, Vol. 137, pp. 328-336, 2016.

[12] K. Ali, L. Khan, Q. Khan, S. Ullah, S. Ahmad, S. Mumtaz, and F. W. Karam, "Robust Integral Backstepping Based Nonlinear MPPT Control for a PV System", Energies, Vol. 12, pp. 1-20, 2019.

[13] K. S. Tey , S. Mekhilef, M. Seyedmahmoudian, B. Horan, A. T. Oo, and A. Stojcevski, "Improved Differential evolution-based MPPT Algorithm Using SEPIC for PV Systems Under Partial Shading Conditions and Load Variation", IEEE Transactions on Industrial Informatics, Vol. 14, pp. $22-43,2018$.

[14] S. Kolesnik and A. Kuperman, "On the Equivalence of Major Variable-Step-Size MPPT Algorithms", IEEE Journal of Photovoltaics, Vol. 6, pp. 590-594, 2016.

[15] J. Ahmed and Z. Salam, "A Modified P\&O Maximum Power PointTracking Method With Reduced Steady-State Oscillation and Improved Tracking Efficiency", IEEE Transactions on Sustainable Energy, Vol. 7, pp. 1506-1515, 2016.

[16] M. A. Elgendy and D. J. Atkinson, "Experimental investigation of the incremental conductance maximum power point tracking algorithm at high perturbation rates", IET Renewable Power Generation, Vol. 10, pp. 133139, 2016.

[17] H. Po-Chen, P. Bo-Rei, L. Yi-Hua, C.Yu-Shan, and H. Jia-We, "Optimization of a fuzzy-logiccontrol-based MPPT algorithm using the particle swarm optimization technique" Energies, Vol. 8, pp. 5338-5360, 2015.

[18] M. Guisser, A. EL-Jouni, and EL. H. Abdelmounim, "Robust Sliding Mode MPPT Controller Based on High Gain Observer of a Photovoltaic Water Pumping System",
International Review of Automatic Control, Vol. 7, pp. 225-232, 2014.

[19] M. Keddar, M. L. Doumbia, M. Della, K. Belmokhtar, and A. Midoun, "Interconnection Performance Analysis of Single Phase Neural Network-Based NPC and CHB Multilevel Inverters for Grid-connected PV Systems", International Journal of Renewable Energy Research, Vol. 9, pp. 1451-1461, 2019.

[20] A. D. Martin, J. M. Cano, and J. F. A. Silva, "Backstepping control of smart grid-connected distributed photovoltaic power supplies for telecom equipment", IEEE Transactions on Energy Conversion, Vol. 30, pp. 1496-1504, 2015.

[21] M. R. Mojallizadeh and M. A. Badamchizadeh, "Second-order fuzzy sliding-mode control of photovoltaic power generation systems", Solar Energy, Vol.149, pp. 332-340,2017.

[22] R. Wai, C. Lin, W. Wu, and H. Huang, "Design of backstepping control for high-performance inverter with stand-alone and grid-connected power-supply modes", IET Power Electronics, Vol. 6, pp. 752-762, 2013.

[23] A. Menadi, S. Abdeddaim, A. Ghamri, and A. Betka, "Implementation of fuzzy-sliding mode based control of a grid-connected photovoltaic system", ISA Transactions, Vol. 58, pp. 586-594, 2015.

[24] K. Rahrah, D. Rekioua , T. Rekioua, and S. Bacha, "Photovoltaic pumping system in Bejaia climate with battery storage", International Journal of Hydrogen Energy, Vol. 40, pp. 13665-13675, 2015.

[25] M. Y. Suberu, M. W. Mustafa, and N. Bashir, "Energy storage systems for renewable energy power sector integration and mitigation of intermittency", Energy Rev. Vol. 35, pp. 499514, 2014.

[26] J. Yu, P. Shi, and W. Dong, "Observer and command-flter-based adaptive fuzzy output feedback control of uncertain nonlinear systems", IEEE Transactions on Industrial Electronics, Vol. 62, pp. 5962-5970, 2015.

[27] W. Dong, J. A. Farrell, and M. M. Polycarpou, "Command filtered adaptive backstepping", IEEE Transactions on Control Systems Technology, Vol. 20, pp. 566-580, 2012.

[28] J. A. Farrell, M. Polycarpou, and M. Sharma, "Command filtered backstepping", IEEE Transactions on Automatic Control, Vol. 54, pp. 1391-1395, 2009.

[29] H. A. K. Singh, I. Hussain, and B. Singh "Double-Stage Three-Phase Grid-Integrated Solar PV System With Fast Zero Attracting 
Normalized Least Mean Fourth Based Adaptive Control", IEEE Transactions on Industrial Electronics, Vol. 65, pp. 3921-3931, 2018.

[30] A. K. Pani and N. Nayak, "A Short Term Forecasting of PhotoVoltaic Power Generation Using Coupled Based Particle Swarm Optimization Pruned Extreme Learning Machine", International Journal of Renewable Energy Research, Vol. 9, pp. 1190-1202, 2019.

[31] C. Aouadi, A. Abouloifa, A. Hamdoun, and Y. Boussairi, "Backstepping Based Control of PV system Connected to the Grid", International Journal of Computer and Information Technology, Vol. 3, pp. 1021-1026, 2014.

[32] S. Sivakumar, M. J. Sathik, P. S. Manoj, and G. Sundararajan, "An assessment on performance of DC-DC converters for renewable energy applications", Elsevier Renewable and Sustainable Energy Reviews, Vol. 58, pp.14751485, 2016.

[33] A. Mlayah and A. Khedher, "Sliding Mode Control Strategy for Solar Charging of High Energy Lithium Batteries", International Journal of Renewable Energy Research, Vol. 8, No. 3, pp. 1621-1623, 2018.

[34] K. R. Bharath, H. Choutapalli, and P. Kanakasabapathy, "Control of Bidirectional DC-DC Converter in Renewable based DC Microgrid with Improved Voltage Stability", International Journal of Renewable Energy Research, Vol. 8, pp. 872-1630, 2018.

[35] B. Selim, K. Ekrem, and K. Ali, "A simpler single-phase single-stage grid connected PV system with maximum power point tracking controller", Elektronika ir elektrotechnika, Vol. 21, pp. $44-47,2015$. 